\title{
APONTAMENTOS INICIAIS SOBRE QUALIDADE EDUCACIONAL: RESULTADOS DO IDEB E FATORES SOCIOECONÔMICOS ${ }^{1}$
}

\author{
ANOTACIONES INICIALES SOBRE CALIDAD EDUCACIONAL: \\ RESULTADOS DEL “IDEB” Y FACTORES SOCIOECONÓMICOS
}

\author{
INITIAL NOTES ON EDUCATIONAL QUALITY: THE IDEB RESULTS \\ AND SOCIOECONOMIC FACTORS
}

\author{
Liliane Ribeiro de MELLO ${ }^{2}$ \\ Regiane Helena BERTAGNA ${ }^{3}$
}

RESUMO: Este trabalho aponta uma discussão inicial sobre a qualidade da educação brasileira obtida através do Índice de Desenvolvimento da Educação Básica (IDEB). Foi elaborado a partir da abordagem qualitativa com análise documental e bibliográfica, utilizando dados do IDEB, taxas de analfabetismo, Produto Interno Bruto per capita, Produto Interno Bruto (PIB) e Índice de Desenvolvimento Humano (IDH) dos estados brasileiros. Apontam-se estes indicadores sem a pretensão de analisá-los estatisticamente, mas para incitar a reflexão/problematização entendendo que a qualidade educacional depende de muitos fatores, como as condições sociais e econômicas dos alunos, o que requer políticas públicas efetivas para obter melhoria a todos.

PALAVRAS-CHAVE: Qualidade educacional. IDEB. Fatores socioeconômicos. Políticas Educacionais.

RESUMEN: Este trabajo presenta una discusión inicial sobre la calidad de la educación brasileña observada por medio del "Índice de Desarrollo de la Educación Básica" (IDEB). Fue elaborado desde el abordaje cualitativo con análisis documental y bibliográfico, utilizando datos del IDEB, tasas de analfabetismo, Producto Interno Bruto per capita, Producto Interno Bruto (PIB) e Índice de Desarrollo Humano (IDH) de los estados brasileños. Se apunta estos indicadores sin la pretensión de analizarlos estadísticamente, pero para llevar a la reflexión/problematización, comprendiendo que la calidad educacional depende de muchos factores, como las condiciones sociales y económicas de los alumnos, lo que requiere políticas públicas efectivas para obtener mejorías a todos.

\footnotetext{
${ }^{1}$ Este artigo foi apresentado no XXVI Simpósio Brasileiro de Política e Administração da Educação, organizado pela ANPAE, no eixo-temático: Políticas públicas, financiamento, avaliação e gestão da educação, realizado de 27 a 30 de maio de 2013, em Recife-PE, fato que possibilitou sua reestruturação e aprimoramento.

${ }_{2}^{2}$ Pedagoga pela Unesp/IB-Rio Claro e mestranda no Programa de Pós-Graduação em Educação da mesma instituição. Área de avaliação e políticas educacionais. Integrante do GREPPE (Grupo de Estudos e Pesquisas em Política Educacional), seção Rio Claro. Email: lilirm@ rc.unesp.br

${ }^{3}$ Professora Doutora em Educação vinculada ao Departamento de Educação da Unesp/IB-Rio Claro. Área de avaliação, políticas e pesquisas educacionais. Vice coordenadora do GREPPE (Grupo de Estudos e Pesquisas em Política Educacional), seção Rio Claro. Email: regiane@ @rc.unesp.br
} 
PALABRAS CLAVE: Calidad educacional. IDEB. Factores socioeconómicos. Políticas Educacionales.

ABSTRACT: This paper brings a initial discussion about brazilian education quality, obtained through the IDEB - Índice de Desenvolvimento da Educação Básica (Brazilian Education Development Index). This work was drawn from a qualitative approach together documentary and bibliographic analisys, using IDEB data, illiteracy rate, GDP per capita, GDP and Human Development Index (HDI) of brazilian states. These indicators was shown without pretension of statistical analisys, but urging a thinking/problematization for to understand that the education quality depends on many factors like social and economic conditions of students, which requires effective public policies for improving for everyone.

KEYWORDS: Education quality. Socioeconomic factors. Educational policy.

\section{Introdução}

Os resultados do Índice de Desenvolvimento da Educação Básica (IDEB) têm se apresentado como uma das formas para designar a qualidade das escolas brasileiras. Deste modo, nota-se que apesar deste índice ser elaborado a fim de evidenciar as prioridades para a formulação de políticas públicas que auxiliem a melhoria do ensino no país, tem sido cada vez mais recorrente o uso de seus resultados para uma responsabilização descontextualizada sobre o mau desempenho das escolas e culpabilização pelos problemas com evasão, reprovação e aprovação, sem que outros fatores relacionados ao contexto em que a escola se insere sejam analisados.

Esta postura de responsabilização, por sua vez, parece contribuir para que o Estado reconfigure sua obrigação de prover o direito de todos à educação de qualidade (com oferta de mais aporte técnico, pedagógico e financeiro), disseminando uma lógica mercantil de competitividade e meritocracia entre as instituições para a promoção desta qualidade. Assim, há necessidade de aprofundar o conhecimento sobre aspectos sociais mais amplos para poder compreender os percalços da educação brasileira por se tratar de uma sociedade desigual.

Nota-se que a Constituição Federal de 1988 (CF/88) e a Lei de Diretrizes e Bases para Educação Brasileira (LDB) n 9394/96 não esclarecem o que seja a "garantia de padrão de qualidade" que consta em seus artigos 206 e $2^{\circ}$, respectivamente. E apesar da LDB, art. $9^{\circ}$, inciso VI, apresentar a avaliação do rendimento escolar relacionada à melhoria da qualidade educacional, não apresenta claramente quais as prioridades e ações que devam ser destinadas para esta melhoria. Portanto, a legislação que serve de 
fundamento para as políticas públicas educacionais não permite a compreensão clara e objetiva de qualidade, fragilizando a forma de regulação e organização dos sistemas de ensino público.

Compreende-se a complexidade em se determinar o que seja qualidade uma vez que ela está relacionada a interesses, significações e valores em um determinado contexto sócio-histórico (CORRÊA, 2003; DIAS SOBRINHO, 2004; GENTILI, 1995; SILVA, 2009; entre outros), no entanto, como tem sido recorrente a ênfase do discurso político da qualidade educacional, isto instiga a necessidade de entender quais os valores e interesses que estão incorporados nestes discursos.

A ênfase na qualidade obtida através do IDEB, quando analisada a partir de suas relações com o contexto político e histórico brasileiro se remete à reforma da administração pública do Brasil, com início no governo Fernando Henrique Cardoso (FHC), em consonância a um panorama global de mudanças de gestão pública por conta da crise do capitalismo (FRIGOTTO; CIAVATTA, 2003). Esta reforma tem como uma de suas características principais o enaltecimento do gerencialismo no serviço público com foco na regulação/controle de resultados e que remete a minimização do Estado, ou seja, tornando-o um Estado "regulador ou avaliador", diminuindo sua função de executor (repassando, então, serviços à iniciativa privada). Nesse sentido, observam-se também as influências de organismos internacionais para que as reformas e o incentivo ao controle de resultados fossem difundidos no contexto brasileiro (DIAS SOBRINHO, 2002; SILVA, 2009).

Então, concomitantemente a reforma do Estado, também ocorreu a reforma na educação brasileira, que teve sua qualidade impregnada da visão empresarial, tomando a avaliação como um instrumento para o controle dos resultados, sem considerar aspectos mais amplos de formação e tampouco a desigualdade das regiões e estados brasileiros (DIAS SOBRINHO, 2002; SILVA, 2009).

É preciso levar em conta que, às questões que envolvem domínio de conhecimentos, códigos, linguagens e raciocínio lógico, próprios da natureza da formação escolar, somam-se outras, como vida familiar, ambiência cultural, condições de transporte, de alimentação, acessibilidade a livros diversos, hábitos de leitura, acesso a equipamentos tecnológicos, que, juntos, constituem a amplitude da formação. Por opção política, esses últimos elementos não são considerados nos critérios de avaliação (SILVA, 2009, p.220). 
Em 2007, o Ministério da Educação (MEC), no governo Lula, criou o Índice de Desenvolvimento da Educação Básica (IDEB). Este índice é calculado pelo Instituto Nacional de Estudos e Pesquisas Educacionais Anísio Teixeira (INEP) e é composto pelos resultados da Avaliação Nacional do Rendimento Escolar (Anresc), ou Prova Brasil, concomitantemente ao fluxo escolar, composto pelas taxas de aprovação, reprovação e evasão (INEP, 2007), sendo, portanto, uma qualidade obtida por meio de dados quantitativos.

Desta forma se deflagra, no contexto da educação brasileira, as avaliações em larga escala que compõem índices de qualidade, os quais enfatizam resultados criando rankings de escolas, muitas vezes, sem analisar os diversos problemas enfrentados por profissionais de educação e alunos de escolas que obtém baixo desempenho nessas classificações.

Considerando que a sociedade brasileira é desigual, tem-se que a desigualdade de oportunidades advinda da desigualdade social interfere na aprendizagem das crianças e adolescentes, neste sentido, faz necessário um conceito de qualidade que permita compreender a complexidade educacional brasileira para não agravar ou acirrar ainda mais a desigualdade social, e consequentemente, educacional.

Nesta perspectiva, aponta-se a qualidade social da educação que propõe um olhar mais subjetivo e compreensivo para a escola, considerando as condições de vida dos sujeitos e os aspectos valorativos da ação educativa um direito de todos e não um privilégio, com potencial para a transformação/emancipação (GENTILI, 1995; PARO, 2008; SILVA, 2009). Esta concepção de qualidade educacional está atrelada a uma aprendizagem significativa, onde os conhecimentos historicamente produzidos deveriam ser apropriados pelos estudantes de forma crítica e criativa.

Compreende-se, portanto, que a qualidade não pode ser restrita apenas ao desempenho dos estudantes em uma determinada prova/teste e fluxo escolar, dado que exige uma contextualização de muitos fatores que estão para além do resultado de uma prova e/ou culpa da unidade pela evasão ou reprovação. Necessita de uma visão social mais ampla para análise de problemas de exclusão que estão além dos muros da escola e faz parte de uma sociedade desigual.

Embora nível socioeconômico seja um nome elegante e dissimulador das situações de desigualdade social, ele é fundamental para se entender o impacto dessa desigualdade social na educação. Nem todas as camadas sociais sofrem da mesma forma com as agruras da 
realidade escolar do país - as camadas populares sofrem mais. (FREITAS, 2007, p. 971).

Sendo assim, fez-se necessário refletir sobre que outros fatores incidem/contribuem também para a promoção da qualidade educacional.

Neste trabalho, utilizou-se da análise documental e bibliográfica para iniciar a discussão de temática tão instigante e complexa. Realizou-se um breve levantamento de dados sobre analfabetismo, Produto Interno Bruto (PIB), PIB per capita, Índice de Desenvolvimento Humano dos estados brasileiros ${ }^{4}$, para refletir sobre os resultados e projeções do Índice de Desenvolvimento da Educação Básica (IDEB) tendo em vista seus limites e suas possibilidades.

Desta forma, a seguir apresenta os resultados e projeções do IDEB por estado para verificar as relações com outros fatores importantes que podem incidir nos resultados, mas que não são considerados por este índice. Ressalta-se que os dados são apresentados em uma perspectiva de incitação à reflexão e problematização, sem intenção de desenvolver uma abordagem estatística dos indicadores sociais, econômicos e educacionais brasileiros.

\section{Analisando os resultados e as projeções do ideb com relação aos dados socioeconômicos dos estados brasileiros}

Diante deste contexto histórico de reforma do Estado e da educação, podemos evidenciar no documento intitulado Planejamento Político-Estratégico 1995-1998 (BRASIL, 1995a), publicado pelo MEC, em maio de 1995, os elementos de uma reforma necessária para elevar o padrão de escolarização no Brasil, como a descentralização da execução (como exemplo, o movimento de municipalização do ensino fundamental) e as avaliações sistemáticas do desempenho dos alunos e das instituições de ensino (como exemplo, o Sistema Nacional de Avaliação da Educação Básica - Saeb). Este documento aponta a prioridade no primeiro grau (atual ensino fundamental), o gerencialismo e a ênfase na autonomia escolar como uma forma de responsabilização e; a atuação do MEC, como um órgão regulador e não executor.

\footnotetext{
${ }^{4}$ Sabemos que estes dados não são suficientes para analisar todo o contexto de cada estado, entretanto, serviu-nos, dentro dos limites deste trabalho, como um aporte para nos dar indícios de limites das avaliações e índices que só recorrem ao desempenho dos estudantes e fluxo escolar sem buscar compreender o momento histórico e fatores socioeconômicos que interferem nos resultados.
} 
Em meio a isto, entende-se que a União cria estratégias para centralizar o controle de resultados e responsabilizar as esferas menores - estados e municípios, e estes, por sua vez, os gestores, professores e estudantes - pela qualidade do ensino ofertado, destacando a autonomia como sinônimo de "esforço próprio" para melhorar.

A qualidade educacional, como apontado anteriormente, requer uma contextualização de fatores adversos à escola, sendo mais importante analisar os resultados para superar as discrepâncias do que enaltecê-los através das mídias com ênfase na classificação. Portanto, entende-se que considerar a qualidade obtida por meio de índices que consideram o desempenho em uma prova padronizada e o fluxo escolar sem analisar outros fatores que influenciam a educação é omitir o fato de que em nossa sociedade capitalista há desigualdade e- que esta desigualdade; interfere na aprendizagem dos alunos, ou seja, que esta limita as condições objetivas para que se aprenda.

Pode-se tomar como exemplo o fato de que ter oportunidade de estudar em casa com apoio de outros materiais (jornais, livros, internet, etc.) e dos pais escolarizados seria algo importante para auxiliar e motivar os estudos, consequentemente, melhorando o desempenho e valorizando a importância de permanência na escola, ou seja, indiretamente incidindo nos índices, mas esta situação não é comum para todas as crianças e adolescentes por existir diferentes condições sociais e não porque os professores e gestores não se esforçam para que aprendam, mas pelo contrário, poderiam estar fazendo uma grande diferença para o desenvolvimento da aprendizagem de seus alunos, porém, estando limitados pelo capital cultural destes.

É com base em Bourdieu (1998) que se apoia o conceito de capital cultural como facilitador das condições de aprendizagem. Este se difere muito entre as pessoas que convivem em uma sociedade desigual, a qual tudo está atrelado ao culto do capital (cultural, social e econômico).

Bourdieu (1998) apresenta a crítica às teorias do capital humano, que reconhecem que o investimento em educação retorna em elevação social no nível individual e de avanços para a sociedade auxiliando no desenvolvimento tecnológico e na melhor produtividade, dizendo que "sujeitam-se a deixar escapar, por um paradoxo necessário, o mais oculto e determinante socialmente dos investimentos educativos, a saber, a transmissão doméstica do capital cultural" (p.73).

O capital cultural, para o autor, existe em três formas (Bourdieu, 1998, p.74-79): 
a) estado incorporado, que está relacionado ao sujeito e sua incorporação dos objetos culturais que possui, aos quais despende seu tempo (e, então, inclui-se o tempo da inculcação e assimilação por contato no âmbito familiar), fazendo parte de sua singularidade biológica consistindo em um bem simbólico cuja transmissão e acumulação depende da totalidade de tempo de socialização, que apesar de haver ligação com o capital econômico tem variação de acordo com as capacidades biológicas individuais;

b) estado objetivado, que está relacionado aos bens materiais adquiridos, cuja a apropriação pode ser material (relação de dependência ao capital econômico) e simbólica (relação de dependência ao capital cultural), ou seja, os bens materiais meramente como meios lucrativos, visto como produto, faz perder-se o status de dominação, ao passo em que se incorpora os benefícios de utilização de forma particular;

c) estado institucionalizado, que está relacionado aos diplomas e certificações que o indivíduo adquire com aprimoramento de conhecimento.

A partir dos diferentes níveis de capital cultural, vemos que comprometer-se a melhorar a aprendizagem dos estudantes em nível nacional exige muita responsabilidade dos entes federados, em regime de colaboração, e superar as dicotomias regionais para além do que o índice indica.

Estas colocações de Bourdieu (1998) provocaram a análise de outros fatores que poderiam ser problematizados juntamente com os atuais resultados do IDEB por estado, tentando evidenciar que outros aspectos poderiam ser considerados na produção dos diferentes desempenhos.

A fim de explorar os resultados e projeções do IDEB e compreender um pouco mais sobre o contexto social e econômico brasileiro busca-se refletir sobre os resultados do IDEB 2011 e as projeções para 2021, apresentados pelo MEC/Inep, juntamente com os dados estatísticos do Instituto Brasileiro de Geografia e Estatística (IBGE) e do Programa das Nações Unidas para o Desenvolvimento (PNUD) sobre aspectos socioeconômicos dos estados brasileiros.

Gentili (1995) defende que qualidade não se trata de favorecer o melhor para minorias, porque isto é privilégio, tem-se que ofertar uma educação melhor para todos, de maneira a agregar qualidade aos sistemas de ensino que atendem a classe popular (maioria).

Pode-se observar com base em Cury (2005) e em Freitas (2007) que para ambos o fato de vivermos em uma sociedade com condições de vida distintas requer políticas que garantam o direito à educação de qualidade a todos e não a uma minoria. Freitas (2007) destaca que uma educação para a pobreza exige mais gastos, mais investimentos. 
Freitas (2007) ainda afirma que os gastos com a educação, redução de número de alunos por sala, ampliação do número de escolas, etc., são necessários, principalmente, para ensinar a pobreza:

[...] pois ela exige estratégias pedagógicas mais caras, já que mais personalizadas. Não poderíamos ter o número de alunos elevado em sala de aula, o que demandaria mais escolas. Não poderíamos tratar diferenciadamente a pobreza, do ponto de vista metodológico, deixando-a em trilhas secundárias que a remetem ao nada. Tudo isso custa. Seria melhor assistir a sua passagem pelo sistema e, por que não, de certa forma facilitá-la? (FREITAS, 2007, p. 981)

Desta forma, é preciso questionar se o IDEB contempla todos os aspectos que incidem na qualidade da educação. As avaliações em larga escala são interessantes, pois fornecem uma base para políticas públicas por apontar os níveis de aprendizagem dos estudantes das redes de ensino e as defasagens educacionais (desempenho e idadesérie), mas de fato tem-se prevalecido a sua utilização para a responsabilização vertical (de cima para baixo) e não corresponsabilização (FREITAS, 2012).

Analisando-se os resultados de 2011 e as projeções de 2021 do IDEB, conforme o quadro 1, para os estados das regiões Norte e Nordeste, evidenciamos que as médias são menores ou iguais do que as médias projetadas para o Brasil e, por outro lado, os estados das regiões Sul e Sudeste têm resultados e projeções iguais ou acima da média, o que pode ser reflexo da desigualdade entre as regiões mais desenvolvidas (Sul e Sudeste) e as menos desenvolvidas (Norte e Nordeste) do Brasil. 
Quadro 1 - Resultados do IDEB 2011 e projeções para 2021, por estado brasileiro e Distrito Federal

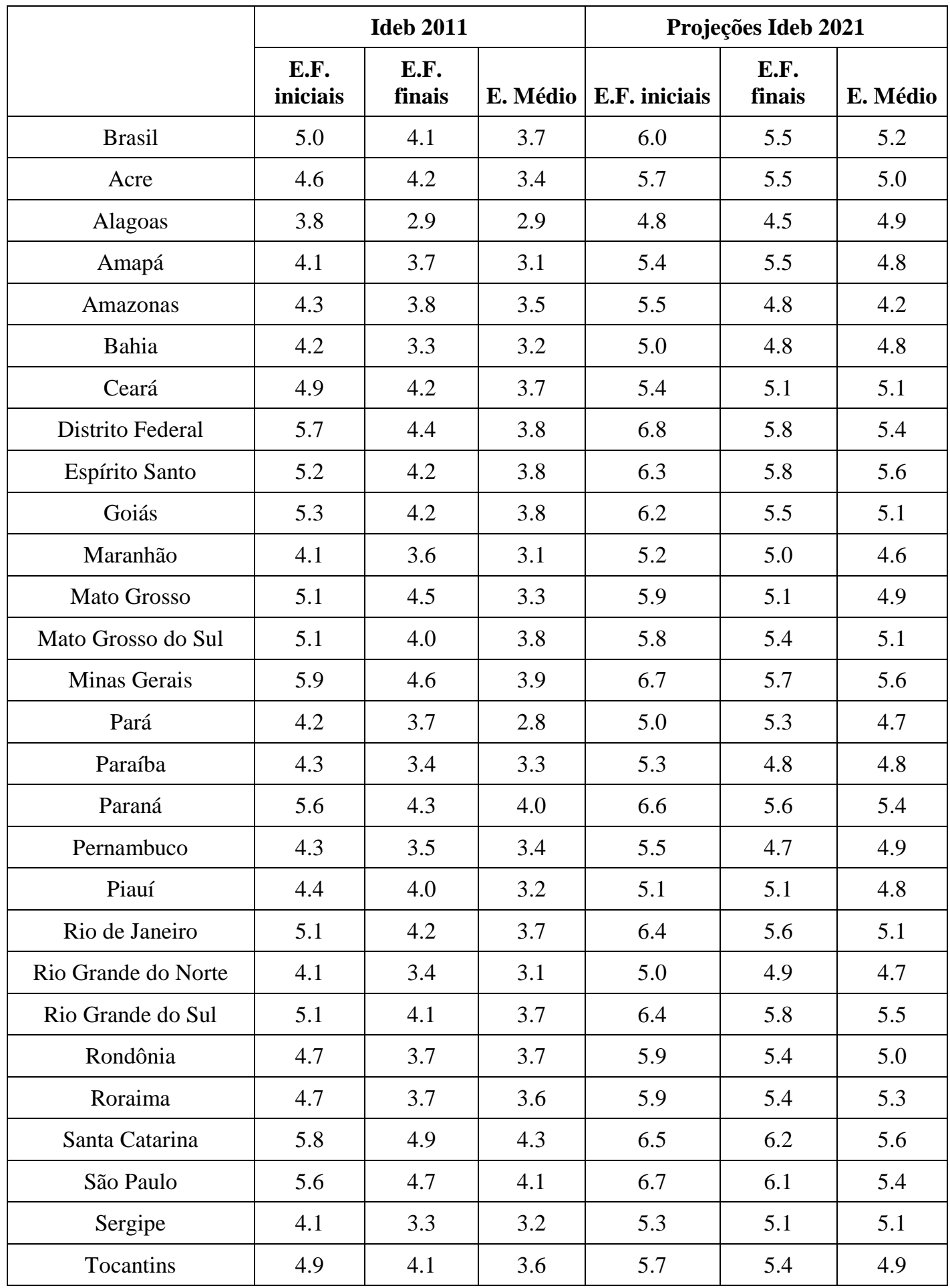

Fonte: As autoras com base nos dados do MEC/Inep.

Para melhor compreender a realidade de cada estado brasileiro buscaram-se os dados do IBGE e do PNUD, abaixo apresentados 
Quadro 2 - Dados de analfabetismo, PIB per capita, PIB e IDH dos estados brasileiros e Distrito Federal

\begin{tabular}{|c|c|c|c|c|c|c|c|c|}
\hline \multirow[b]{4}{*}{ Brasil } & \multicolumn{2}{|c|}{ Taxa de analfabetismo } & \multicolumn{2}{|c|}{ PIB per capita* } & \multicolumn{2}{|c|}{ PIB** } & \multirow{2}{*}{\multicolumn{2}{|c|}{$\begin{array}{c}\text { Índice de } \\
\text { Desenvolvimento } \\
\text { Humano - IDH*** }\end{array}$}} \\
\hline & \multirow{2}{*}{ Total } & \multirow{2}{*}{$\begin{array}{c}\% \\
\text { população } \\
\text { do estado }\end{array}$} & \multirow{2}{*}{ Total } & \multirow{2}{*}{$\begin{array}{c}\% \\
\text { relativo }\end{array}$} & \multirow{2}{*}{ Total } & \multirow{2}{*}{$\begin{array}{c}\% \\
\text { nacional }\end{array}$} & & \\
\hline & & & & & & & Valor & \multirow{2}{*}{$\begin{array}{c}\text { Classificação } \\
\text { nacional }\end{array}$} \\
\hline & $13,933,173$ & $10 \%$ & $16,917,66$ & 100,0 & $3,239,404,053$ & 100 & 0,794 & \\
\hline Acre & 80,249 & $16,5 \%$ & $10,697,45$ & 63,2 & $7,386,436$ & 0,23 & 0,751 & $18^{\circ}$ \\
\hline Alagoas & 537,538 & $24,3 \%$ & $6,728,21$ & 39,8 & $21,234,951$ & 0,66 & 0,677 & $27^{\circ}$ \\
\hline Amapá & 37,696 & $8,4 \%$ & $11,816,60$ & 69,8 & $7,404,389$ & 0,23 & 0,780 & $12^{\circ}$ \\
\hline Amazonas & 229,337 & $9,9 \%$ & $14,620,94$ & 86,4 & $49,614,251$ & 1,53 & 0,780 & $13^{\circ}$ \\
\hline Bahia & $1,729,297$ & $16,6 \%$ & $9,364,71$ & 55,4 & $137,074,671$ & 4,23 & 0,742 & $19^{\circ}$ \\
\hline Ceará & $1,176,582$ & $18,8 \%$ & $7,686,62$ & 45,4 & $65,703,761$ & 2,03 & 0,723 & $22^{\circ}$ \\
\hline $\begin{array}{l}\text { Distrito } \\
\text { Federal }\end{array}$ & 68,114 & $3,5 \%$ & $50,438,46$ & 298,1 & $131,487,268$ & 4,06 & 0,874 & $1^{\mathrm{o}}$ \\
\hline $\begin{array}{l}\text { Espírito } \\
\text { Santo }\end{array}$ & 219,762 & $8,1 \%$ & $19,145,17$ & 113,2 & $66,763,012$ & 2,06 & 0,802 & $7^{\circ}$ \\
\hline Goiás & 362,829 & $8,0 \%$ & $14,446,68$ & 85,4 & $85,615,344$ & 2,64 & 0,800 & $10^{\circ}$ \\
\hline Maranhão & 948,163 & $20,9 \%$ & $6,259,43$ & 37,0 & $39,854,677$ & 1,23 & 0,683 & $26^{\circ}$ \\
\hline $\begin{array}{l}\text { Mato } \\
\text { Grosso }\end{array}$ & 191,616 & $8,5 \%$ & $19,087,30$ & 112,8 & $57,294,192$ & 1,77 & 0,796 & $11^{\circ}$ \\
\hline $\begin{array}{l}\text { Mato } \\
\text { Grosso do } \\
\text { Sul }\end{array}$ & 141,141 & $7,7 \%$ & $15,406,96$ & 91,1 & $36,368,094$ & 1,12 & 0,802 & $8^{\circ}$ \\
\hline $\begin{array}{l}\text { Minas } \\
\text { Gerais }\end{array}$ & $1,264,896$ & $8,3 \%$ & $14,328,62$ & 84,7 & $287,054,748$ & 8,86 & 0,800 & $9^{\circ}$ \\
\hline Pará & 613,616 & $11,7 \%$ & $7,859,19$ & 46,5 & $58,401,830$ & 1,80 & 0,755 & $17^{\circ}$ \\
\hline Paraíba & 616,581 & $21,9 \%$ & $7,617,71$ & 45,0 & $28,718,598$ & 0,89 & 0,718 & $23^{\circ}$ \\
\hline Paraná & 506,096 & $6,3 \%$ & $17,779,11$ & 105,1 & $189,991,949$ & 5,87 & 0,820 & $6^{\circ}$ \\
\hline Pernambuco & $1,177,654$ & $18,0 \%$ & $8,901,93$ & 52,6 & $78,428,308$ & 2,42 & 0,718 & $24^{\circ}$ \\
\hline Piauí & 524,706 & $22,9 \%$ & $6,051,10$ & 35,8 & $19,032,665$ & 0,59 & 0,703 & $25^{\circ}$ \\
\hline $\begin{array}{l}\text { Rio de } \\
\text { Janeiro }\end{array}$ & 539,383 & $4,3 \%$ & $22,102,98$ & 130,7 & $353,878,136$ & 10,92 & 0,832 & $4^{\circ}$ \\
\hline $\begin{array}{l}\text { Rio Grande } \\
\text { do Norte }\end{array}$ & 441,723 & $18,5 \%$ & $8,893,90$ & 52,6 & $27,904,989$ & 0,86 & 0,738 & $21^{\circ}$ \\
\hline $\begin{array}{l}\text { Rio Grande } \\
\text { do Sul }\end{array}$ & 383,277 & $4,5 \%$ & $19,778,39$ & 116,9 & $215,863,879$ & 6,66 & 0,832 & $5^{\circ}$ \\
\hline Rondônia & 99,451 & $8,7 \%$ & $13,455,56$ & 79,5 & $20,236,194$ & 0,62 & 0,776 & $14^{\circ}$ \\
\hline Roraima & 31,152 & $10,3 \%$ & $13,270,47$ & 78,4 & $5,593,491$ & 0,17 & 0,750 & $16^{\circ}$ \\
\hline $\begin{array}{c}\text { Santa } \\
\text { Catarina }\end{array}$ & 202,452 & $4,1 \%$ & $21,214,53$ & 125,4 & $129,806,256$ & 4,01 & 0,840 & $2^{o}$ \\
\hline São Paulo & $1,402,548$ & $4,3 \%$ & $26,202,22$ & 154,9 & $1,084,353,490$ & 33,47 & 0,833 & $3^{\circ}$ \\
\hline
\end{tabular}




\begin{tabular}{|c|c|c|c|c|c|c|c|c|}
\hline Sergipe & 278,221 & $18,4 \%$ & $9,787,25$ & 57,9 & $19,767,111$ & 0,61 & 0,742 & $20^{\circ}$ \\
\hline Tocantins & 129,093 & $13,1 \%$ & $11,277,70$ & 66,7 & $14,571,366$ & 0,45 & 0,756 & $15^{\circ}$ \\
\hline
\end{tabular}

Fonte: As autoras com dados do IBGE (Censo Demográfico 2010; Dados economia: Tabela 1 Produto Interno Bruto a preços correntes e Produto Interno Bruto per capita segundo as Grandes Regiões, as Unidades da Federação e os municípios - 2005-2009) e do PNUD.

*Taxa de analfabetismo da população de 15 anos ou mais de idade - 2010.

**PIB per capita e PIB - 2005.

*** IDH calculado pelo PNUD em 2005, divulgado em Boletim Regional do Banco Central do Brasil, 20095.

De acordo com os dados do IBGE e do PNUD sobre os estados, pode-se notar a relação entre os altos índices de analfabetismo, os recursos financeiros do estado e a condições de vida da população com seu desempenho no IDEB. Por exemplo, como apresentado no quadro 1, o estado de Alagoas obteve as piores notas do IDEB 2011em todos os anos/séries avaliados e é, conforme o quadro 2, o estado brasileiro com maior taxa de analfabetismo proporcional a sua população $(24,3 \%)$, tem o terceiro menor PIB per capita (39,8\% comparado ao valor médio nacional), pouca participação no montante total do PIB nacional $(0,66 \%)$ e ainda é o estado brasileiro com menor Índice de Desenvolvimento Humano - IDH (0,0677 em 2005), o que demonstra que se trata de um estado com menos recursos e, consequentemente, sua população sofre com este fato, inclusive a educação fica debilitada, já que é um dos fatores considerados no cálculo do IDH e, portanto, os resultados do IDEB também ressaltam suas dificuldades.

Em contraposição tem-se, por exemplo, o Distrito Federal, conforme quadro 1, com um dos melhores resultados no IDEB 2011, e no quadro 2 é o estado que tem a menor taxa de analfabetismo $(3,5 \%)$, maior PIB per capita $(298,1 \%$ comparado ao valor médio nacional), apesar de seu PIB total ser o $7^{\circ}$ do Brasil (4,06\% de participação no PIB nacional) e melhor IDH (0,874 em 2005).

Estes dados, principalmente o IDH que considera fatores como saúde (longevidade), educação (média de anos de estudos dos adultos e expectativa de escolaridade) e renda (Renda Nacional Bruta - RNB - per capita com poder de paridade de compra), servem para apresentar um panorama geral da população, mas também tem seus limites. Por meio do sítio eletrônico do Programa das Nações Unidas para o Desenvolvimento $^{6}$ (PNUD), órgão que calcula os IDHs globais e regionais, entende-se que:

${ }^{5}$ Disponível em: <http://www.bcb.gov.br/pec/boletimregional/port/2009/01/br200901b1p.pdf>.
${ }^{6}$ Disponível em:<http://www.pnud.org.br/IDH/IDH.aspx?indiceAccordion=0\&li=li_IDH>. 
Apesar de ampliar a perspectiva sobre o desenvolvimento humano, o IDH não abrange todos os aspectos de desenvolvimento e não é uma representação da "felicidade" das pessoas, nem indica "o melhor lugar no mundo para se viver". Democracia, participação, equidade, sustentabilidade são outros dos muitos aspectos do desenvolvimento humano que não são contemplados no IDH. (PNUD, s.d., s/p).

Ainda, sem a pretensão de enrijecer os olhares, se considerar que "Como todas as médias, o IDH mascara a desigualdade na distribuição do desenvolvimento humano entre a população no nível de país" (PNUD, s.d., não paginado) e, com base no Relatório do Desenvolvimento Humano global de 2011 (PNUD, 2011), levar em conta ainda o Índice de Desenvolvimento Humano Ajustado à Desigualdade (IDHAD), composto pelo cálculo de IDH juntamente com os dados de desigualdade de acesso e distribuição dos três fatores considerados (saúde, educação e renda), nota-se que este apresenta um pouco mais a realidade do Brasil, dado que enquanto o país é o $84^{\circ}$ no IDH de 2011 (com valor de 0,718), ele perde 13 colocações no ranking global considerando o IDHAD calculado para o mesmo ano, obtendo o valor de 0,519 (PNUD, 2011). Assim, nota-se que o Brasil apresenta uma desigualdade muito grande, o que agrava os problemas sociais se considerarmos sempre (e apenas) as médias potenciais.

Esclarecemos que não se trata de uma visão linear de comparação entre dados do IDEB e outros fatores socioeconômicos. Não é proposta deste estudo uma análise estatística dos dados, mas busca-se alertar sobre as condições de vida nos estados brasileiros que afetam as condições de aprendizagem. Trata-se de fatores que dialogam e permitem destacar as possíveis relações entre desenvolvimento econômico e social dos estados com os resultados que estes obtiveram nas avaliações padronizadas e condições de permanência e aprovação, entendendo-se que isto requer uma contextualização maior de condições de vida para considerar a qualidade de redes de ensino e enfatizar a necessidade de reivindicar que políticas educacionais promovam mais equidade e oportunidade de melhoria a todos.

\section{Alcançar a qualidade é uma questão de prêmio ou de direito?}

Discutir e analisar as propostas para a melhoria da qualidade é essencial para os sistemas de ensino brasileiro, mas esta não deveria ser regida pela evocação de esforço próprio para alcançá-la e, sim, a perpetuação da ideia de qualidade como direito de todos. 
O foco na responsabilização vertical, ou seja, aquela que remete a culpa a um contexto micro (à escola e seus gestores, professores e estudantes) pela (má) qualidade do ensino, firmando-se na aplicação de conceitos e "fórmulas" empresariais para a melhoria da escola pública (FREITAS, 2012) não parece a mais adequada para promoção de qualidade frente a um país com uma diversidade e desigualdade bastante acentuada como mostram os dados apresentados.

O Brasil parece aderir à responsabilização sem questionar apontamentos pertinentes como a concepção de educação que subjaz a proposta. A implementação de avaliações em larga escala em caráter censitário parece surgir como estratégia para controlar ações e responsabilizar as escolas. Os resultados remetem a punição, como, por exemplo, menos recursos do Programa Dinheiro Direto na Escola (PDDE) para as escolas que não atingirem as metas.

Freitas (2007) aponta suas críticas ao sistema de avaliação de ensino e ao IDEB pela sua lógica de responsabilização criando-se o quase-mercado (devido a divulgação de resultados por escola e escolha de pais pela matrícula de seus filhos na melhores escolas - cobrança por melhoria de ensino via accontability - responsabilização sob ideologia liberal) que iguala qualidade a acesso e considera que desigualdade de resultados existe porque depende de fatores como a competência e comprometimento individual.

Todas estas ações encobrem o pano de fundo mencionado antes: nossa sociedade produz tamanha desigualdade social que as instituições que nela funcionam, se nenhuma ação contrária for adotada, acabam por traduzir tais desigualdades como princípio e meio de seu funcionamento (Bourdieu \& Passeron, 1975; Baudelot \& Establet, 1986). Todos concordamos em que isso não é desejável, mas meras políticas de equidade apenas tendem a ocultar o problema central: a desigualdade socioeconômica. Não é sem razão que os melhores desempenhos escolares estão nas camadas com melhor nível socioeconômico, brancas (Cf. Miranda, 2006, entre outros estudos disponíveis). (FREITAS, 2007 p. 969).

O mesmo autor aponta para a questão dinâmica das duas vertentes opostas do cenário educacional: fracasso por fatores internos (pedagógicos) e fracasso por fatores externos (sociais) da escola, que segundo o autor são causas pertinentes do fracasso e assim:

Se isso é verdadeiro, as políticas de equidade devem ser associadas às políticas de redução e eliminação das desigualdades sociais, fora da escola. Isso implica continuar a produzir a crítica do sistema social 
que cerca a escola, além de introduzir a importância do nível socioeconômico como variável relevante nas análises de avaliação do desempenho do aluno e da escola. (FREITAS, 2007, p.971).

O conceito de responsabilização bilateral defendida por Freitas (2007) remete a considerar estas duas vertentes em uma propositura de relação mais harmoniosa entre a comunidade escolar (gestores, professores, estudantes, pais) com o poder público para a garantia de qualidade educacional a todos.

Isto remete a pensar em uma responsabilização conjunta, mas ainda assim, há o problema de que não é possível - somente considerando as médias do IDEB - alcançar a qualidade educacional para todos. De fato, as distorções sociais aqui apresentadas demonstram um grande desafio para que toda a população se aproprie das melhorias de qualidade da educação.

Refletindo sobre as medidas políticas que podem remeter às melhorias nota-se a necessidade de mais investimento da União para auxiliar estados e municípios que obtém baixo desempenho, dado que financiamento é necessário também para se garantir a qualidade (melhoria e manutenção da estrutura física, compra de materiais e equipamentos pedagógicos, formação de professores, etc.).

Outra ação que pode auxiliar as escolas é ter a opção de comissões locais para avaliar redes e unidades de ensino, por facilitar um aprofundamento e um contato mais próximo com as escolas e conhecer as dificuldades que estas enfrentam.

De fato, entende-se que não se trata de aceitar a qualidade como mérito/prêmio daqueles que se esforçam; consta na CF/88 e na LDB/96 que a educação de qualidade é direito de todos a ser garantido pelo Estado.

\section{Considerações finais}

Com base nos dados socioeconômicos dos estados brasileiros se evidencia a desigualdade de nossa sociedade, e, consequentemente, nota-se que as escolas têm relações muito imbricadas com o sistema econômico vigente.

A ênfase em resultados das avaliações sem contextualização das causas e a responsabilização individualizada e punitiva, possivelmente promoverá e intensificará a desigualdade social. A concepção de educação à mercê do mercado não permitirá a garantia do direito de todos à educação de qualidade. 
O IDEB não estimula uma compreensão dos problemas enfrentados por diversas escolas brasileiras e parece prevalecer um discurso taxativo de obtenção da qualidade como mérito por meio de punições e premiações, não como direito.

Faz-se necessário uma responsabilização conjunta de profissionais da educação, pais e Estado para promover a qualidade e formular políticas educacionais mais efetivas (tanto em relação ao financiamento quanto apoio técnico e pedagógico, etc.) para obter melhorias nos sistemas de ensino com vistas à superação das desigualdades escolares e sociais.

Percebe-se que a qualidade educacional não pode ser contabilizada e nem que se efetivará com professores e gestores trabalhando sob pressão para alcançarem resultados previamente estabelecidos sem contextualização. Um exemplo disto é o caso dos Estados Unidos apresentado por Ravitch (2011).

Diante dos apontamentos acima colocados, se evidencia que o governo faz uma propagação de uma concepção limitada de qualidade que não considera que as condições de vida de crianças e adolescentes são muito adversas, que há discrepâncias sociais e nas estruturas físicas e pedagógicas das escolas em nosso país e que isso remete à diversidade de níveis de aprendizagem e dificuldades de ensino. Por que não faz diferença se a criança comeu ou não antes de ir à escola para que possa aproveitar seus estudos? Ou ainda, não faz diferença se a escola tem ou não carteiras e cadeiras adequadas, um telhado sem goteiras e se conta com saneamento básico, além de poder contar com equipamentos tecnológicos?

Afinal, educação não se restringe a memorização de conteúdo, é uma construção permanente de valores, conhecimentos e competências que extrapolam os muros da escola e remete às ações na vida econômica, social e política do país.

A qualidade educacional para todos já encontrou espaço no discurso, mas ainda há distorções na prática. Assim, a luta em defesa dos direitos sociais torna-se cada vez mais necessária para que o desejo de uma sociedade mais igualitária seja concretizado com educação de qualidade como uma obrigação do poder público. É importante que novos olhares sejam lançados sobre a educação e os fatores sociais que se relacionam a ela sejam considerados, tornando as médias e os resultados produzidos apenas elementos para análise e cuidando para que estes não se tornem o objetivo final das políticas educacionais com vistas a prestigiar ou discriminar uma determinada escola. 


\section{REFERÊNCIAS}

BOURDIEU, P. Os três estados do capital cultural. In: NOGUEIRA, M. A.; CATANI, A. (orgs.). Escritos de educação: Pierre Bourdieu. Petrópolis: Vozes, 1998.

BRASIL. Constituição da República Federativa do Brasil. Brasília: D.O.U. de 5 junho de 1988.

BRASIL. Lei n. 9.394, de 20 de dezembro de 1996. Dispõe sobre as Diretrizes e Bases da Educação Nacional. Brasília: D.O.U. de 23 dezembro de 1996.

BRASIL. Ministério da Educação e do Desporto. Planejamento Político-Estratégico 1995/1998. Brasília, maio de 1995 (mimeo).

CORRÊA, B. C. Considerações sobre qualidade na educação infantil. Caderno de Pesquisa, São Paulo, s/v, n.119, p.85-112, jul/2003.

CURY, C. R. J. Políticas inclusivas e compensatórias na educação básica. Cadernos de Pesquisa, São Paulo, vol.35, n.124, p. 11-32, jan./abr. 2005.

DIAS SOBRINHO, J. Campo e caminhos da avaliação: a avaliação da educação superior no Brasil. In: FREITAS, L. C. (org.) Avaliação: construindo o campo e a crítica. Florianópolis: Insular, 2002.

DIAS SOBRINHO, J. Avaliação ética e política em função da educação como direito público ou como mercadoria? Educação \& Sociedade, Campinas, v.25, n.88, p. 703725 , out. 2004.

FREITAS, L. C. Eliminação adiada: o ocaso das classes populares no interior da escola e a ocultação da (má) qualidade do ensino. Educação e Sociedade, Campinas, vol.28, n.100, p. 965-987, out. 2007.

FREITAS, L. C. Os reformadores empresariais da educação: da desmoralização do magistério à destruição do sistema público de educação. Educação e Sociedade, Campinas, vol.33, n.119, p. 379-404, abr./jun. 2012.

FRIGOTTO, G.; CIAVATTA, M. Educação básica no Brasil na década de 1990: subordinação ativa e consentida à lógica do mercado. Educação e Sociedade, Campinas, vol.24, n.82, p. 93-130, abr. 2003.

GENTILI, P. O discurso da "qualidade" como nova retórica conservadora no campo educacional. In: GENTILI, P. \& SILVA, T. T. (org.). Neoliberalismo, qualidade total e educação. Petrópolis: Vozes, 1995.

INSTITUTO NACIONAL DE ESTUDOS E PESQUISAS EDUCACIONAIS ANÍSIO TEIXEIRA (INEP). Índice de Desenvolvimento da Educação Básica (Ideb).

Reynaldo Fernandes. Brasília: Inep, 2007.

INSTITUTO NACIONAL DE ESTUDOS E PESQUISAS EDUCACIONAIS ANÍSIO TEIXEIRA (INEP). Nota Técnica - Índice de Desenvolvimento da Educação Básica (Ideb) de 2011. Brasília, Inep, 2011.

PARO, V. A escola pública que queremos. In: PARO, V. Educação como exercício do poder: crítica ao senso comum em educação. São Paulo: Cortez, 2008.

PROGRAMA DAS NAÇÕES UNIDAS PARA O DESENVOLVIMENTO (PNUD). Relatório do Desenvolvimento Humano 2011. Sustentabilidade e Equidade: Um Futuro Melhor para Todos. New York, USA, 2011. 
RAVITCH, D. Vida e morte do grande sistema escolar americano: como os testes padronizados e os modelos de mercado ameaçam a educação. Tradução de Marcelo Duarte. Porto Alegre: Sulina, 2011.

SILVA, M. A. Qualidade social da educação pública: algumas aproximações. Cadernos Cedes, Campinas, vol. 29, n. 78, p. 216-226, maio/ago. 2009.

\section{Como referenciar este artigo}

MELLO, Liliane Ribeiro de.; BERTAGNA, Regiane Helena. Apontamentos iniciais sobre qualidade educacional: resultados do IDEB e fatores socioeconômicos. Revista Ibero-Americana de Estudos em Educação, Araraquara/SP, v. 11, n. 3, p.1132-1148, 2016. Disponível em: <https://dx.doi.org/10.21723/riaee.v11.n3.6168>. E-ISSN: 19825587.

Submetido em: 27/03/14

Aprovação Final em: 04/07/16 